\title{
Chronic hyperglycemia increases the risk of lateral epicondylitis: the Locomotive Syndrome and Health Outcome in Aizu Cohort Study (LOHAS)
}

\author{
Kenichi Otoshi ${ }^{1 *}$, Misa Takegami ${ }^{2}$, Miho Sekiguchi ${ }^{1}$, Yoshihiro Onishi ${ }^{3}$, Shin Yamazaki ${ }^{4}$, Koji Otani $^{1}$,
} Hiroaki Shishido', Shunichi Fukuhara ${ }^{4}$, Shinichi Kikuchi ${ }^{1}$ and Shinichi Konno ${ }^{1}$

\begin{abstract}
Background: Although humeral epicondylitis is a common health problem, there have been no reports that describe its prevalence in Japanese general population, and relatively little is known about its etiology and associated risk factors.

Questions/purposes: This study aimed to clarify the prevalence of humeral epicondilitis in Japanese general population, and investigate the associated risk factors using the data from a cross-sectional study of the Locomotive Syndrome and Health Outcome in Aizu Cohort Study (LOHAS).
\end{abstract}

Methods: A total of 1,777 participants who participated in health checkups conducted at rural area in Japan in 2010 were enrolled. The prevalence of lateral and medial epicondylitis was investigated. Logistic regression models were performed to examine the relationship between lateral epicondylitis and correlated factors such as occupational status, smoking and alcohol preferences, and medical characteristics.

Results: The overall prevalence of lateral and medial epicondylitis was $2.5 \%$ and $0.3 \%$, respectively. A shortened version of the disabilities of the arm, shoulder and hand (The QuickDASH) score was significantly higher in subjects with lateral epicondylitis than in those without (15.0 \pm 12.7 vs $8.5 \pm 11.1)$. Subjects with definite chronic hyperglycemia (HbA1c $\geq 6.5)$ showed a 3.37-times higher risk of lateral epicondylitis than those with favorable glycemic control (HbA1c < 5.5) (95\% confidence interval (Cl) 1.16-8.56). Age and sex, as well as occupational status, smoking and alcohol preference, and other metabolic factors were not significantly related to higher risk of lateral epicondylitis.

Conclusions: Lateral epicondylitis influences activities of daily living. Chronic hyperglycemia might be one of the risk factor for lateral epicondylitis.

Clinical relevance: Chronic hyperglycemia is significantly associated with lateral epicondylitis.

\section{Background}

Lateral epicondylitis is one of the most prevalent disorders of the upper extremity, clinically defined by lateral elbow pain around the lateral epicondyle of the humerus

\footnotetext{
*Correspondence: kootoshi@fmu.ac.jp

${ }^{1}$ Department of Orthopaedic Surgery, Fukushima Medical University School of Medicine, 1, Hikarigaoka, Fukushima City, Fukushima 960-1295, Japan

Full list of author information is available at the end of the article
}

that is provoked by resisted use of wrist and finger extensor (Walker-Bone et al. 2012).

Lateral epicondilitis is characterized by microtears, collagen degeneration, and angioblastic proliferation of the common extensor tendon (Johnson et al. 2007; Kraushaar and Nirschl 1999; Nirschl and Ashman 2004), and may affect muscle fiber type composition (Ljung et al. 1999), neural drive (Alizadehkhaiyat et al. 2009), and stiffness of the muscle-tendon complex (Chourasia et al. 2012; Sesto et al. 2006).

\section{Springer}


There have been several cross-sectional epidemiologic studies to clarify the etiology and associated risk factors about lateral epicondylitis. A number of studies were carried out among selected occupational populations previously, and suggested an increased risk of epicondylitis associated with strenuous manual tasks such as the repetitive movements of arms and hand with extreme non-neutral postures, static load, and vibration from using handheld vibrating tools (Leclerc et al. 2001). In relation to sports activity, Nirschl and Ashman suggested that the incidence of epicondilitis has been reported to be more often in patient age 35 years or older, high sports activity level, demanding activity technique, and inadequate fitness level (Nirschl and Ashman 2004). Several studies have regarded the relative contributions of preferences and metabolic factors to musculoskeletal disorders. Previous smoking history is an important risk factor for the development of lateral epicondilitis as well as rotator cuff tear and distal biceps tendon rupture (Bodin et al. 2012; Safran and Graham 2002; Titchener et al. 2013), and nicotine tartrate has been shown to induce fibroblast degeneration and irregular fibril organization (Duygulu et al. 2006). Heavy alcohol consumption, more than three standard drinks per day, is associated with an increased risk of early age-related muscular degeneration (Chong et al. 2008). Obesity increases weight on the load-bearing tendons and systemic dysmetabolic factors, triggering subclinical persistent inflammation (Abate et al. 2013; Werner et al. 2005). Hypertension is associated with Achilles tendinopathy, and may have diminution of the local microvascularity as its end-organ effect (Holmes and Lin 2006). Hypercholesterolemia induces cholesterol deposition in the tendons (March et al. 1957). In diabetes, advanced glycation end products deteriorate the biologic and mechanical functions of the tendons and ligaments. However, little is currently known about the relative contributions of preferences and metabolic factors to lateral epicondylitis in the general population (Walker-Bone et al. 2004) and there has been no epidemiologic study reporting the prevalence and determinants of lateral epicondylitis in Japan.

The aim of this large epidemiologic study was to clarify the prevalence of humeral epicondilitis in Japanese general population and investigate the associated risk factors using cross-sectional data from the Locomotive Syndrome and Health Outcome in Aizu Cohort Study (LOHAS) (Otani et al. 2012).

\section{Methods}

Locomotive syndrome, which is a new concept proposed by the Japanese Orthopedic Association in 2007, referring to conditions under which elderly individuals have been receiving care services, or high-risk conditions under which they may soon require care services, due to problems with the locomotive systems (Nakamura 2009). As the population of Japan is aging rapidly, the number of elderly who need nursing care is increased sharply which read to heavy financial burden on society.

The LOHAS is an ongoing prospective cohort study that aims to evaluate the risk of cardiovascular disease, quality of life, medical costs, and mortality attributable to locomotive dysfunction in Japanese subjects (Otani et al. 2012). The subjects were community dwelling individuals over 40 years old who were National Health Insurance (NHI) beneficiaries receiving regular health check-ups conducted by local government each year, in MinamiAizu Town and Tadami in Fukushima prefecture, Japan. Minami-Aizu-Town and Tadami-Town are located in valleys surrounded by mountains in north-eastern Japan, at longitude $139^{\circ} 46^{\prime} \mathrm{N}$, latitude $37^{\circ} 12^{\prime} \mathrm{E}$; and longitude $139^{\circ} 18^{\prime} \mathrm{N}$, latitude $37^{\circ} 21^{\prime} \mathrm{E}$, respectively. The weather in the region is cool, with average daily temperatures of 9.7 ${ }^{\circ} \mathrm{C}$ in Minami-Aizu town and $10.6{ }^{\circ} \mathrm{C}$ in Tadami Town. These towns are adjoining and have areas of approximately 745 and $886 \mathrm{~km}^{2}$, respectively. The total population of Minami-Aizu Town was 35,728 according to the 2010 population census, with $69.4 \%$ of residents over 40 years old and $21.2 \%$ over 75 years old. The total population of Tadami Town was 4,932 with $72.3 \%$ of residents over 40 years old and $25.8 \%$ over 75 years old. The main industry in the region is agriculture and most resident have remained in the two towns for many years, making this community appropriate for a cohort study. Eligibility criteria included persons who had participated in annual health checkups conducted in 2010. The Research Ethics Committee of our institute approved the study protocol, and written informed consent was obtained from all subjects.

\section{Survey methodology}

This study comprised the following three items: self-completed questionnaire, special health checkup, and physical examination of locomotive function. Self-completed questionnaire forms were distributed to the subjects before an annual health checkup and collected on the day of the checkup. Items on the questionnaire included the subject's sex, age, occupation, pain and disability of the upper extremities, and general health-related quality of life (HRQOL). A special health checkup was performed to measure height, weight, waist circumference, systolic blood pressure (SBP), diastolic blood pressure (DBP), and glycated hemoglobin (HbA1c), as well as serum levels of low-density lipoprotein cholesterol (LDL-C), high-density lipoprotein cholesterol (HDL-C), and triglycerides (TG). In addition, subjects were questioned regarding their personal medical, smoking, and alcohol history. 
Physical examination was performed by experienced orthopedic surgeons to investigate locomotive functions and disorders of the subjects, including joint range of motion, muscle power, and pain provocation test. To achieve the best possible accuracy, the orthopedic surgeons were trained before performing the examinations.

\section{Definition of humeral epicondylitis}

The diagnosis of epicondylitis was based on symptoms and clinical signs during a standardized physical examination. The diagnostic criteria for lateral epicondylitis were (1) tenderness at the lateral epicondyle of the humerus and (2) lateral elbow pain around the lateral epicondyle of the humerus on resisted extension of the wrist or finger with the elbow extended. The diagnostic criteria for medial epicondylitis were (1) tenderness at the medial epicondyle of the humerus and (2) medial elbow pain around the medial epicondyle of the humerus on resisted flexion of the wrist or on resisted forearm pronation with the elbow extended.

\section{Occupational status}

The subject's current or most long-lasting former occupation was investigated, and classified into the following four categories: manual, nonmanual, service, and the other. Manual work included agriculture, transportation, and manufacturing. Nonmanual work included office work, administration, and professional. Service work included sales and the service industry. The population of unemployed subjects was defined as no occupation (Otani et al. 2012).

\section{Smoking and alcohol preference}

Smoking status and alcohol consumption were investigated by self-administrated questionnaire. Smoking status was categorized into three groups: current smoker (the subject smoked at the time of the checkup), former smoker (the subject had smoked and did not currently smoke), and never smoker. Alcohol consumption was categorized into 4 groups: consumes alcohol every day, sometimes, rarely, and never.

\section{Medical characteristics}

Body mass index (BMI) was calculated from the height and weight measured during the special health checkup. Overweight was defined as BMI $\geq 25 \mathrm{~kg} / \mathrm{m}^{2}$ based on the criteria of the Japan Society for the Study of Obesity (Examination Committee of Criteria for 2002).

Hypertension was defined according to the Japanese Society of Hypertension Guidelines for the Management of Hypertension (Ogihara et al. 2009), and categorized into three types based on SBP and DBP: normal
(SBP $<130 \mathrm{mmHg}$ and DBP $<85 \mathrm{mmHg}$ ), definite (SBP $\geq 140 \mathrm{mmHg}$ or DBP $\geq 90 \mathrm{mmHg}$ ), and borderline.

Hyperlipidemia was defined according to the criteria recommended by the Japan Atherosclerosis Society (Hata et al. 2002). The subject must satisfy at least one of the following three criteria: fasting serum LDL-C level $>140 \mathrm{mg} / \mathrm{dL}$, TG level $>150 \mathrm{mg} / \mathrm{dL}$, or HDL-C level $<40 \mathrm{mg} / \mathrm{dL}$.

Chronic hyperglycemia was defined according to the criteria recommended by the Japan Diabetes Society (2010). It is categorized into three types based on HbA1c: favorable control (HbA1c < 5.5), suspected (HbA1c, 5.66.4 ), and definite (HbA1c $\geq 6.5$ ).

Metabolic syndrome was defined according to the criteria of the Examination Committee of Criteria for Metabolic Syndrome in Japan (2005) as the subject's waist circumference must be at least $85 \mathrm{~cm}$ for men and $90 \mathrm{~cm}$ for women. In addition, the subject must satisfy at least two of the following three criteria: TG level $\geq 150 \mathrm{mg} /$ $\mathrm{dL}$, HDL-C level $\leq 40 \mathrm{mg} / \mathrm{dL}$, or be receiving lipid-lowering therapy; SBP $\geq 130 \mathrm{mmHg}, \mathrm{DBP} \geq 85 \mathrm{mmHg}$, or be receiving antihypertensive therapy; and fasting plasma glucose level $\geq 110 \mathrm{mg} / \mathrm{dL}$ or be receiving antihyperglycemic therapy.

\section{Upper extremity disability and HRQOL}

Upper extremity disability was assessed using the Japanese version of the shortened Disabilities of the Arm, Shoulder and Hand (The QuickDASH) questionnaire (Imaeda et al. 2006). HRQOL was assessed using the Medical Outcome Study Short Form 12-Item Health Survey (SF-12) (Fukuhara and Suzukamo 2004). The subject's responses to the SF-12 questions were used to determine scores for mental component summary (MCS) and physical component summary (PCS). The scales for MCS and PCS were derived from eight different subscales: physical functioning role (physical, bodily pain, general health, vitality) and social functioning role (emotional health, mental health).

\section{Statistical analysis}

Both baseline characteristics of analyzed and excluded subjects and clinicodemographic characteristics according to presence of lateral epicondylitis were compared using the Chi squared test for categorical variables and the $t$ test for continuous variables. Logistic regression models were performed to examine the relationship between lateral epicondylitis and correlated factors. All tests of statistical significance were two-tailed. P values of less than 0.05 were considered to indicate statistical significance. All analyses were conducted using JMP version 10.0.2 (SAS Institute Inc, Cary, NC). 


\section{Results}

\section{Subject attributes}

Of the 2,505 participants in the LOHAS baseline survey, 728 were excluded for various reasons, leaving 1,777 ultimately enrolled in the present analysis (Fig. 1). Characteristics of the study population are described in Table 1. The subjects included in this analysis were more likely to be younger, male, a smoker, drinker, have a lower QuickDASH score, and have a higher PCS score on the SF-12.

\section{Prevalence of epicondylitis}

The prevalences of lateral and medial epicondylitis are described in Table 2. The overall prevalence of lateral and medial epicondylitis was $2.5 \%$ and $0.3 \%$, respectively. Four subjects had concurrent lateral and medial epicondylitis, with a prevalence of $0.2 \%$. No significant difference was seen in the prevalence of lateral and medial epicondylitis when comparing men and women and different age groups. There was a trend towards an increased prevalence of medial epicondylitis in men and women between ages 40-59 years. Since the prevalence of medial epicondylitis was too low to analyze statistical determinations, no statistical determinations could be made.

\section{Clinicodemographic factors in subjects with and without lateral epicondylitis}

The frequencies of clinicodemographic factors in subjects with and without lateral epicondylitis are described in Table 3. Only chronic hyperglycemia was associated with lateral epicondilitis whereas there were no significant differences in age or sex between subjects with and without lateral epicondylitis. Smoking and alcohol preference, other medical characteristics, and occupational status also showed no association with lateral epicondylitis. The QuickDASH score was significantly higher in those with lateral epicondylitis compared with those without $(15.0 \pm 12.7$ vs $8.5 \pm 11.1)$. In HRQOL, there were no

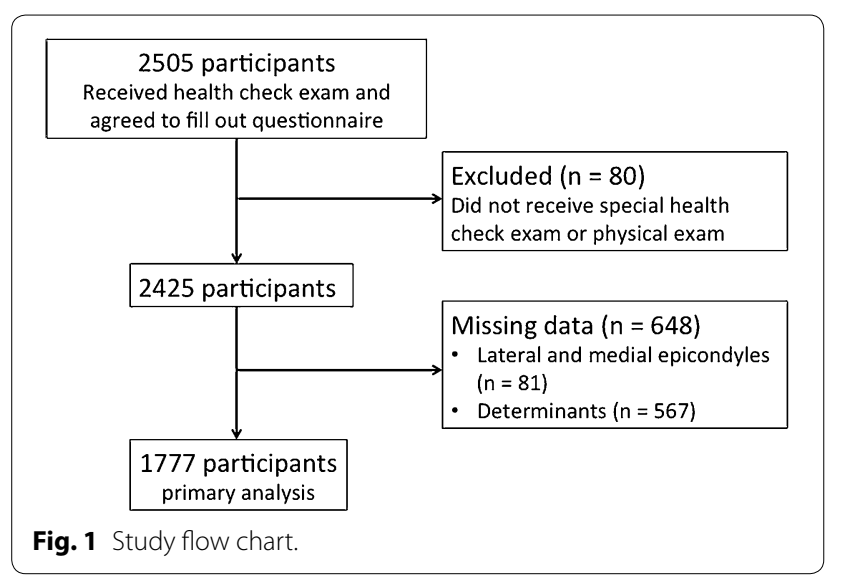

significant differences in PCS or MCS score on the SF-12 between subjects with and without lateral epicondylitis.

In multivariable analysis, after controlling for the effects of other covariates, we found that chronic hyperglycemia had a significant association with lateral epicondylitis (Table 4). Subjects with definite chronic hyperglycemia $(\mathrm{HbA} 1 \mathrm{c} \geq 6.5)$ showed a 3.37 times higher risk of lateral epicondylitis than those with favorable glycemic control (HbA1c < 5.5) (95\% CI 1.16-8.56). The odds ratio for suspected chronic hyperglycemia (HbA1c 5.6-6.4) was also high (1.60 times), but not significantly. Age and sex, as well as occupational status, smoking and alcohol preference, and other medical characteristics showed no significant association with higher risk of lateral epicondylitis.

\section{Discussion}

According to previous studies, the prevalence of lateral and medial epicondylitis has been reported to be $0.7-$ 23 \% (Allander 1974; Descatha et al. 2013; Herquelot et al. 2013; McCormack et al. 1990; Ono et al. 1998; Shiri et al. 2006; Walker-Bone et al. 2004) and 0.2-5.0 \% (Ono et al. 1998; Shiri et al. 2006; Verhaar 1994; Viikari-Juntura et al. 1991; Walker-Bone et al. 2012), respectively, and tend to be higher in the working population compared with the general population. In this study, the overall prevalence of lateral and medial epicondylitis was $2.5 \%$ and $0.3 \%$, respectively, which are comparable with previous epidemiologic studies conducted in the general population.

Regarding individual factors, increasing age has been reported to be possible risk factors for epicondylitits, and the highest prevalence has been reported among subjects aged 40-60 years (Leclerc et al. 2001; McCormack et al. 1990; Ono et al. 1998; Verhaar 1994; Viikari-Juntura et al. 1991). In this study, the prevalence of lateral epicondylitis was higher in subjects aged 40-59 years in both men and women whereas there was no significant difference. Increasing degenerative change of common extensor tendon with advancing age and sustained high physical activity level as their younger age might have an important effect on the development of lateral epicondilitis in middle-aged group (Hamilton 1986).

An association between gender and epicondylitis is still controversial (Leclerc et al. 2001; Ono et al. 1998; ViikariJuntura et al. 1991; Walker-Bone et al. 2004).

There was no difference in the prevalence of lateral epicondilitis between male and female in this study, while several reports described a higher risk in female sex (Ono et al. 1998; Viikari-Juntura et al. 1991).

Several studies have suggested an increased risk of epicondylitis in association with strenuous manual tasks (Descatha et al. 2003, 2013; Herquelot et al. 2013; Walker-Bone et al. 2003a, b). Repetitive forceful flexing 
Table 1 Baseline characteristics of the analysis population

\begin{tabular}{|c|c|c|c|c|}
\hline & All subjects $(n=2,425)$ & Excluded subjects $(n=648)$ & Analyzed subjects $(n=1,777)$ & $P$ value \\
\hline \multicolumn{5}{|l|}{ Age (years) } \\
\hline $40-59$ & $370(15.3)$ & $114(17.6)$ & $256(14.4)$ & \multirow[t]{3}{*}{$<0.001$} \\
\hline $60-69$ & $847(34.9)$ & $172(26.5)$ & $675(38.0)$ & \\
\hline$\geq 70$ & $1,208(49.8)$ & $362(55.9)$ & $846(47.6)$ & \\
\hline \multicolumn{5}{|l|}{ Sex } \\
\hline Male & $985(40.6)$ & $211(32.6)$ & $774(43.6)$ & \multirow[t]{2}{*}{$<0.001$} \\
\hline Female & $1,440(59.4)$ & $437(67.4)$ & $1,003(56.4)$ & \\
\hline \multicolumn{5}{|c|}{ Occupational categories } \\
\hline No occupation & $1,430(59.0)$ & $401(61.9)$ & $1,029(57.9)$ & \multirow{5}{*}{0.059} \\
\hline Nonmanual & $134(5.5)$ & $33(5.1)$ & $101(5.7)$ & \\
\hline Service & $250(10.3)$ & $63(9.7)$ & $187(10.5)$ & \\
\hline Manual & $426(17.6)$ & $93(14.4)$ & $333(18.7)$ & \\
\hline Other & $185(7.6)$ & $58(9.0)$ & $127(7.1)$ & \\
\hline \multicolumn{5}{|l|}{ Smoking status } \\
\hline Never & $1,578(65.2)$ & $463(71.9)$ & $1,115(62.7)$ & \multirow[t]{3}{*}{$<0.001$} \\
\hline Past & $587(24.2)$ & $127(19.7)$ & $460(25.9)$ & \\
\hline Current & $256(10.6)$ & $54(8.4)$ & $202(11.4)$ & \\
\hline \multicolumn{5}{|c|}{ Alcohol consumption } \\
\hline Never & $770(32.1)$ & $222(35.6)$ & $548(30.8)$ & \multirow[t]{4}{*}{$<0.001$} \\
\hline Every day & $559(23.3)$ & $108(17.3)$ & $451(25.4)$ & \\
\hline Sometimes & $454(18.9)$ & $122(19.6)$ & $332(18.7)$ & \\
\hline Rarely & $617(25.7)$ & $171(27.5)$ & $446(25.1)$ & \\
\hline \multicolumn{5}{|l|}{ BMI $\left(\mathrm{kg} / \mathrm{m}^{2}\right)$} \\
\hline$<25$ & $1,134(63.2)$ & $220(63.2)$ & $1,124(63.3)$ & \multirow[t]{2}{*}{0.990} \\
\hline$\geq 25$ & $781(36.8)$ & $128(36.8)$ & $653(36.7)$ & \\
\hline \multicolumn{5}{|c|}{ Past medical history } \\
\hline \multicolumn{5}{|l|}{ Hypertension } \\
\hline No & $1,234(51.6)$ & $332(54.0)$ & $902(50.8)$ & \multirow[t]{2}{*}{0.168} \\
\hline Yes & $1,158(48.4)$ & $283(46.0)$ & $875(49.2)$ & \\
\hline \multicolumn{5}{|c|}{ Cerebrovascular disease } \\
\hline No & 2,277 (95.4) & $583(95.6)$ & $1,694(95.3)$ & \multirow[t]{2}{*}{0.804} \\
\hline Yes & $110(4.6)$ & $27(4.4)$ & $83(4.7)$ & \\
\hline \multicolumn{5}{|l|}{ Cardiac disease } \\
\hline No & $2,186(91.5)$ & $563(91.8)$ & $1,623(91.3)$ & \multirow[t]{2}{*}{0.697} \\
\hline Yes & $204(8.5)$ & $50(8.2)$ & $154(8.7)$ & \\
\hline \multicolumn{5}{|l|}{ Hyperlipidemia } \\
\hline No & $1,653(69.3)$ & $433(71.0)$ & $1,220(68.7)$ & \multirow[t]{2}{*}{0.282} \\
\hline Yes & 734 (30.8) & $177(29.0)$ & $557(31.3)$ & \\
\hline \multicolumn{5}{|l|}{ Diabetic disease } \\
\hline No & 2,191 (91.9) & $564(92.8)$ & $1,627(91.6)$ & \multirow[t]{2}{*}{0.348} \\
\hline Yes & $194(8.1)$ & $44(7.2)$ & $150(8.4)$ & \\
\hline Subjective outco & $\operatorname{an}(\mathrm{SD})$ & & & \\
\hline The QuickDASH & $8.9(11.4)$ & $9.7(11.9)$ & $8.7(11.2)$ & 0.046 \\
\hline SF-12 & & & & \\
\hline PCS & $31.9(12.2)$ & $30.8(12.1)$ & $32.2(12.2)$ & 0.030 \\
\hline MCS & $45.8(8.9)$ & $45.9(8.3)$ & $45.8(9.1)$ & 0.892 \\
\hline
\end{tabular}

Values represent $\mathrm{n}(\%)$ of subjects.

$B M I$ body mass index, DASH disabilities of arm, shoulder and hand, SF-12 short form 12, PCS physical component summary, MCS mental component summary, SD standard deviation. 
Table 2 Prevalence of lateral, medial, and concurrent lateral and medial epicondylitis by age and sex

\begin{tabular}{|c|c|c|c|c|c|c|c|}
\hline & \multirow{2}{*}{$\begin{array}{l}\text { Total } \\
\text { n }\end{array}$} & \multicolumn{2}{|c|}{ Lateral epicondylitis } & \multicolumn{2}{|c|}{ Medial epicondylitis } & \multicolumn{2}{|c|}{$\begin{array}{l}\text { Concurrent lateral } \\
\text { and medial epicondylitis }\end{array}$} \\
\hline & & $\mathrm{n}$ & Prevalence (\%) & $n$ & Prevalence (\%) & $n$ & Prevalence (\%) \\
\hline \multicolumn{8}{|l|}{ Male } \\
\hline $40-59$ & 113 & 4 & 3.5 & 0 & 0 & 0 & 0 \\
\hline $60-69$ & 295 & 7 & 2.4 & 1 & 0.3 & 1 & 0.3 \\
\hline$\geq 70$ & 366 & 9 & 2.5 & 0 & 0 & 0 & 0 \\
\hline All & 774 & 20 & 2.6 & 1 & 0.1 & 1 & 0.1 \\
\hline \multicolumn{8}{|l|}{ Female } \\
\hline $40-59$ & 143 & 5 & 3.5 & 2 & 1.4 & 1 & 0.7 \\
\hline $60-69$ & 380 & 6 & 1.6 & 1 & 0.3 & 0 & 0 \\
\hline$\geq 70$ & 480 & 13 & 2.7 & 2 & 0.4 & 2 & 0.4 \\
\hline All & 1,003 & 24 & 2.4 & 5 & 0.5 & 3 & 0.3 \\
\hline Total & 1,777 & 44 & 2.5 & 6 & 0.3 & 4 & 0.2 \\
\hline
\end{tabular}

or extending of the elbow and wrist, and twisting, rotating, and screwing motions of the forearm with extreme non-neutral postures have been associated with medial or lateral epicondylitis (Bernard 1997; Descatha et al. 2003, 2013; Haahr and Andersen 2003; Herquelot et al. 2013; Kurppa et al. 1991; Ono et al. 1998; Walker-Bone et al. 2003a, b). According to our results, unexpectedly, there was no significant difference in prevalence of lateral epicondilitis among occupational categories. One of the considerable reasons is that the categories using in this study might not reflect the actual amount of manual tasks involving the upper extremities. In addition, the majority of the residents, including unemployed subjects, would be engaged in agriculture as a family business along with their own occupation. To make a precise assessment of association between the occupation and lateral epicondilitis, detailed evaluation of the actual amount of manual tasks at each occupation would be needed.

Regarding metabolic factors, subjects with chronic hyperglycemia demonstrated a significantly higher risk of lateral epicondylitis compared with those with favorable glycemic control in this study. To the present, several experimental and clinical studies have described the association between diabetes mellitus and tendon degeneration. The animal study using the diabetic rat tendonitis models showed that the number of accumulated neutrophils, macrophages, and proliferative cells was decreased, as was the density of newly formed blood vessels in the paratenon and core of the tendon, and that these alterations eventually perturb tendon healing and remodeling (Chibinou and Frenette 2004). Ahmed et al. also reported that tendon healing in a diabetic rat model was impaired, mainly due to altered expression of collagen and matrix metalloproteinase (MMPs), reflecting decreased degradation of matrix proteins and impaired tissue remodeling (Ahmed et al. 1985). Burner et al. reported that decreased synthesis or sulfation of glycosaminoglycans induced by reduction in prostaglandin (PG) levels may contribute to the tendon pathology observed clinically in diabetes (Burner et al. 2012). In the clinical study, Siddiqui et al. reported that patients with diabetes mellitus had significantly higher pain score, reduced grip strength, and higher recurrence rate after open surgical release for lateral epicondylitis, and concluded that poorer healing and remodeling of the tendon might result in persistence of symptoms or subsequent recurrence after surgery (Siddiqui et al. 2011). While some reports described no relationship between diabetes mellitus and lateral epicondylitis (Titchener et al. 2013), our result and previous studies suggests that it might be appropriate to certify that chronic hyperglycemia could be one of the risk factors for lateral epicondylitis.

There are several limitations when interpreting the results of this study. First, the area surveyed in this study was located in very rural area of Japan with a particularly aged- population. In addition, our study population was not sufficiently large to estimate accurately the prevalence and risk factors of lateral epicondilitis in the Japanese general population. Similar epidemiologic study should be done in urban area to eliminate the regional differences and enhance the reliability of statistical analysis.

Second, there was no information on practicing sports such as tennis and golf in this study. To assess the involvement in sports activity to the epicondilitis would be an issue in the future.

Third, there might be some selection bias in this study. Since subjects voluntarily attended the health checkup, 
Table 3 Clinicodemographic variables according to presence of lateral epicondylitis

\begin{tabular}{|c|c|c|c|c|}
\hline & Total $(n=1,777)$ & $\begin{array}{l}\text { Subjects with lateral } \\
\text { epicondylitis }(n=44)\end{array}$ & $\begin{array}{l}\text { Subjects without lateral } \\
\text { epicondylitis }(n=1,733)\end{array}$ & $\begin{array}{l}P \\
\text { value }\end{array}$ \\
\hline \multicolumn{5}{|l|}{ Age (years) } \\
\hline $40-59$ & $256(14.4)$ & $9(20.5)$ & $247(14.3)$ & \multirow[t]{3}{*}{0.360} \\
\hline $60-69$ & $675(38.0)$ & $13(29.5)$ & $662(38.2)$ & \\
\hline$\geq 70$ & $846(47.6)$ & $20(50.0)$ & $824(47.5)$ & \\
\hline \multicolumn{5}{|l|}{ Sex } \\
\hline Male & 774 (43.6) & $20(45.5)$ & $754(43.5)$ & \multirow[t]{2}{*}{0.797} \\
\hline Female & $1,003(56.4)$ & $24(54.5)$ & $879(56.5)$ & \\
\hline \multicolumn{5}{|l|}{ Occupational categories } \\
\hline No occupation & $1,029(57.9)$ & $23(52.3)$ & $1,006(58.1)$ & \multirow[t]{5}{*}{0.933} \\
\hline Nonmanual & $101(5.7)$ & $3(6.8)$ & $98(5.6)$ & \\
\hline Service & $187(10.5)$ & $6(13.6)$ & $181(10.4)$ & \\
\hline Manual & $333(18.7)$ & $9(20.5)$ & $324(18.7)$ & \\
\hline Other & $127(7.1)$ & $3(6.8)$ & $124(7.2)$ & \\
\hline \multicolumn{5}{|l|}{ Smoking status } \\
\hline Never & $1,115(62.7)$ & $26(59.1)$ & $1,089(62.8)$ & \multirow[t]{3}{*}{0.848} \\
\hline Past & $460(25.9)$ & $13(29.5)$ & $447(25.8)$ & \\
\hline Current & $202(11.4)$ & $5(11.4)$ & $197(11.4)$ & \\
\hline \multicolumn{5}{|l|}{ Alcohol consumption } \\
\hline Never & $548(30.8)$ & $16(36.4)$ & $532(30.7)$ & \multirow[t]{4}{*}{0.542} \\
\hline Every day & $451(25.4)$ & $13(29.5)$ & $438(25.3)$ & \\
\hline Sometimes & $332(18.7)$ & $5(11.4)$ & $327(18.9)$ & \\
\hline Rarely & $446(25.1)$ & $10(22.7)$ & $436(25.4)$ & \\
\hline \multicolumn{5}{|l|}{ Obesity } \\
\hline Normal (BMl<25) & $1,124(63.3)$ & $24(54.5)$ & $1,100(63.5)$ & \multirow[t]{2}{*}{0.225} \\
\hline Overweight (BMI $\geq 25)$ & $653(36.7)$ & $20(45.5)$ & $633(36.5)$ & \\
\hline \multicolumn{5}{|l|}{ Abdominal circumference $(\mathrm{cm})$} \\
\hline Normal & $1,141(64.2)$ & $27(61.4)$ & $1,114(64.3)$ & \multirow[t]{2}{*}{0.690} \\
\hline Abnormal & $636(35.8)$ & $17(38.6)$ & $619(35.7)$ & \\
\hline \multicolumn{5}{|l|}{ Mets } \\
\hline No & $1,458(82.0)$ & $34(77.3)$ & $1,424(82.2)$ & \multirow[t]{2}{*}{0.403} \\
\hline Yes & $319(18.0)$ & $10(22.7)$ & $309(17.8)$ & \\
\hline \multicolumn{5}{|l|}{ Hypertension } \\
\hline Normal & $485(27.3)$ & $12(27.3)$ & $473(27.3)$ & \multirow[t]{3}{*}{0.923} \\
\hline Borderline & $529(29.8)$ & $12(27.3)$ & $517(29.8)$ & \\
\hline Definite & $763(42.9)$ & $20(45.4)$ & $743(42.9)$ & \\
\hline \multicolumn{5}{|l|}{ Hyperlipidemia } \\
\hline Normal & $1,188(66.9)$ & $30(68.2)$ & $1,158(66.8)$ & \multirow[t]{2}{*}{0.850} \\
\hline Definite & $589(33.1)$ & $14(31.8)$ & $575(33.2)$ & \\
\hline \multicolumn{5}{|l|}{ Chronic hyperglycemia } \\
\hline Favorable control $(\mathrm{HbA} 1 \mathrm{C}<5.5)$ & $1,181(66.5)$ & $23(52.3)$ & $1,158(66.8)$ & \multirow[t]{3}{*}{0.025} \\
\hline Suspected $(5.5 \leq \mathrm{HbA} 1 \mathrm{C}<6.4)$ & $498(28.0)$ & $15(34.1)$ & $483(27.9)$ & \\
\hline Definite $(\mathrm{HbA1C} \geq 6.5)$ & $98(5.5)$ & $6(13.6)$ & $92(5.3)$ & \\
\hline \multicolumn{5}{|l|}{ Subjective outcome, mean (SD) } \\
\hline The QuickDASH & $8.7(11.3)$ & $15.0(12.7)$ & $8.5(11.1)$ & $<0.001$ \\
\hline SF-12 & & & & \\
\hline PCS & $32.2(12.2)$ & $29.9(12.1)$ & $32.3(12.2)$ & 0.209 \\
\hline MCS & $45.8(9.1)$ & $43.8(9.5)$ & $45.8(9.1)$ & 0.144 \\
\hline
\end{tabular}

$B M /$ body mass index, Mets metabolic syndrome, SBP systolic blood pressure, DBP diastolic blood pressure, HDL-C high density lipoprotein cholesterol, $L D L-C$ low density lipoprotein cholesterol, TG triglyceride, HbA1c hemoglobin A1c, DASH disabilities of arm, shoulder and hand, SF-12 short form 12, PCS physical component summary, MCS mental component summary, SD standard deviation. 
Table 4 Multivariable odds ratios mutually adjusted for determinants of lateral epicondylitis

\begin{tabular}{|c|c|c|}
\hline & \multicolumn{2}{|c|}{ Lateral epicondylitis } \\
\hline & Odds ratio & $95 \% \mathrm{Cl}$ \\
\hline \multicolumn{3}{|l|}{ Age (years) } \\
\hline $40-59$ & 1 & \\
\hline $60-69$ & 0.51 & $0.21-1.31$ \\
\hline$\geq 70$ & 0.66 & $0.28-1.67$ \\
\hline \multicolumn{3}{|l|}{ Sex } \\
\hline Male & 1 & \\
\hline Female & 1.02 & $0.42-2.55$ \\
\hline \multicolumn{3}{|l|}{ Occupation } \\
\hline No & 1 & \\
\hline Yes & 1.27 & $0.66-2.45$ \\
\hline \multicolumn{3}{|l|}{ Smoking status } \\
\hline Never & 1 & \\
\hline Past & 1.27 & $0.50-3.27$ \\
\hline Current & 1.07 & $0.31-3.18$ \\
\hline \multicolumn{3}{|c|}{ Alcohol consumption } \\
\hline Never & 1 & \\
\hline Current & 0.71 & $0.36-1.42$ \\
\hline \multicolumn{3}{|l|}{ Obesity } \\
\hline Normal & 1 & \\
\hline Overweight & 1.41 & $0.71-2.74$ \\
\hline \multicolumn{3}{|l|}{ Metabolic syndrome } \\
\hline Normal & 1 & \\
\hline Definite & 0.93 & $0.38-2.15$ \\
\hline \multicolumn{3}{|l|}{ Hypertension } \\
\hline Normal & 1 & \\
\hline Borderline & 0.93 & $0.40-2.16$ \\
\hline Definite & 1.04 & $0.50-2.27$ \\
\hline \multicolumn{3}{|l|}{ Hyperlipidemia } \\
\hline Normal & 1 & \\
\hline Definite & 0.81 & $0.40-1.55$ \\
\hline \multicolumn{3}{|c|}{ Chronic hyperglycemia } \\
\hline Favorable control & 1 & \\
\hline Suspected & 1.60 & $0.80-3.10$ \\
\hline Definite & $3.37^{*}$ & $1.16-8.56$ \\
\hline
\end{tabular}

* $P<0.05$.

relatively healthy and health-conscious individuals may have participated in this study, and some individuals who make regular hospital visits may not come for annual health checkup.

Last, since our research was a cross-sectional study, it is not possible to assess a causal relationship between chronic hyperglycemia and lateral epicondylitis. A prospective cohort study should be done to clarify the causal relationship between chronic hyperglycemia and lateral epicondylitis.
In conclusion, the prevalences of lateral and medial epicondylitis in Japanese general population were comparable with previous epidemiologic studies conducted in other countries. Chronic hyperglycemia could be one of the risk factors for lateral epicondylitis.

\section{Authors' contributions}

$\mathrm{KO}$ carried out the survey of the available literature on humeral epicondilitis, performed the statistical analysis and drafted the manuscript. YO performed the statistical analysis. MT, MS, and KO participated in the design of the study and coordination and helped to draft the manuscript. HS, SF, SK, and SK has conceptually reviewed the paper. All authors read and approved the final manuscript.

\section{Author details}

${ }^{1}$ Department of Orthopaedic Surgery, Fukushima Medical University School of Medicine, 1, Hikarigaoka, Fukushima City, Fukushima 960-1295, Japan.

${ }^{2}$ Department of Preventive Medicine and Epidemiologic Informatics, National Cerebral and Cardiovascular Center, 5-7-1, Fujishirodai, Suita City, Osaka 565-8565, Japan. ${ }^{3}$ Institute for Health Outcomes and Process Evaluation Research (iHope International), 513, Nijosagaruakinonomachi, Karasumadori, Chukyoku, Kyoto City, Kyoto 604-084, Japan. ${ }^{4}$ Department of Healthcare Epidemiology, Graduate School of Medicine and Public Health, Kyoto University, 54 Shogoinkawahara-cho, Sakyo-ku, Kyoto, Kyoto 606-8507, Japan.

\section{Acknowledgements}

The authors thank Kazuhide Uesugi, Hiroshi Kobayashi, Nobuyuki Sasaki, and Katsuhiro Yoshida for data collection.

\section{Compliance with ethical guidelines}

\section{Competing interests}

The authors declare that they have no competing interests.

Received: 1 April 2015 Accepted: 31 July 2015

Published online: 11 August 2015

\section{References}

Abate M, Schiavone C, Salini V, Andia I (2013) Occurrence of tendon pathologies in metabolic disorders. Rheumatology (Oxford) 52:599-608. doi:10.1093/rheumatology/kes395

Ahmed AS, Schizas N, Li J, Ahmed M, Östenson CG, Salo P et al (1985) Type 2 diabetes impairs tendon repair after injury in a rat model. J Appl Physiol 2012(113):1784-1791. doi:10.1152/japplphysiol.00767.2012

Alizadehkhaiyat O, Fisher AC, Kemp GJ, Vishwanathan K, Frostick SP (2009) Assessment of functional recovery in tennis elbow. J Electromyogr Kinesiol 19:631-638. doi:10.1016/j.jelekin.2008.01.008

Allander E (1974) Prevalence, incidence, and remission rates of some common rheumatic diseases or syndromes. Scand J Rheumatol 3:145-153

Bernard BP (ed) (1997) Musculoskeletal disorders and workplace factors. A critical review of epidemiologic evidence for work-related musculoskeletal disorders of the neck, upper extremity, and low back. Cincinnati: National Institute for Occupational Safety and Health

Bodin J, Ha C, Sérazin C, Descatha A, Leclerc A, Goldberg M et al (2012) Effects of individual and work-related factors on incidence of shoulder pain in a large working population. J Occup Health 54:278-288

Burner T, Gohr C, Mitton-Fitzgerald E, Rosenthal AK (2012) Hyperglycemia reduces proteoglycan levels in tendons. Connect Tissue Res 53:535-541. doi:10.3109/03008207.2012.710670

Chibinou N, Frenette J (2004) Insulin-dependent diabetes impairs the inflammatory response and delays angiogenesis following Achilles tendon injury. Am J Physiol Regul Integr Comp Physiol 286:952-957

Chong EW, Kreis AJ, Wong TY, Simpson JA, Guymer RH (2008) Alcohol consumption and the risk of age-related macular degeneration: a systematic review and meta-analysis. Am J Ophthalmol 145:707-715. doi:10.1016/j. ajo.2007.12.005 
Chourasia AO, Buhr KA, Rabago DP, Kijowski R, Sesto ME (2012) The effect of lateral epicondylosis on upper limb mechanical parameters. Clin Biomech (Bristol, Avon) 27:124-130. doi:10.1016/j.clinbiomech.2011.08.014

Committee of the Japan Diabetes Society on the Diagnostic Criteria of Diabetes Mellitus (2010) Report of the committee on the classification and diagnostic criteria of diabetes mellitus. J Diabetes Invest 1:212-228

Descatha A, Leclerc A, Chastang JF, Roquelaure Y, Study Group on Repetitive Work (2003) Medial epicondylitis in occupational settings: prevalence, incidence and associated risk factors. J Occup Environ Med 45:993-1001

Descatha A, Dale AM, Jaegers L, Herquelot E, Evanoff B (2013) Self-reported physical exposure association with medial and lateral epicondylitis incidence in a large longitudinal study. Occup Environ Med 70:670-673. doi:10.1136/oemed-2012-101341

Duygulu F, Karaoğlu S, Zeybek ND, Kaymaz FF, Güneş T (2006) The effect of subcutaneously injected nicotine on achilles tendon healing in rabbits. Knee Surg Sports Traumatol Arthrosc 14:756-761

Examination Committee of Criteria for 'Obesity Disease' in Japan, Japan Society for the Study of Obesity (2002) New criteria for 'obesity disease' in Japan. Circ J 66:987-992

Examination Committee of Criteria for Metabolic Syndrome (2005) The definition and criteria of metabolic syndrome. J Jpn Soc Intern Med 94:794-809 (in Japanese)

Fukuhara S, Suzukamo Y (2004) Manual of SF-36v2 Japanese version. Institute for Health Outcomes and Process Evaluation Research, Kyoto

Haahr JP, Andersen JH (2003) Physical and psychosocial risk factors for lateral epicondylitis: a population based case-referent study. Occup Environ Med 60:322-329

Hamilton PG (1986) The prevalence of humeral epicondylitis: a survey in general practice. J R Coll Gen Pract 36:464-465

Hata Y, Mabuchi H, Saito Y, Itakura H, Egusa G, Ito H, Working Committee on JAS Guideline for Diagnosis and Treatment of Hyperlipidemias et al (2002) Report of the Japan Atherosclerosis Society (JAS) guideline for diagnosis and treatment of hyperlipidemia in Japanese adults. J Atheroscler Thromb 9:1-27

Herquelot E, Bodin J, Roquelaure Y, Ha C, Leclerc A, Goldberg M et al (2013) Work-related risk factors for lateral epicondylitis and other cause of elbow pain in the working population. Am J Ind Med 56:400-409. doi:10.1002/ ajim.22140

Holmes GB, Lin J (2006) Etiologic factors associated with symptomatic achilles tendinopathy. Foot Ankle Int 27:952-959

Imaeda T, Toh S, Wada T, Uchiyama S, Okinaga S, Kusunose K et al (2006) Validation of the Japanese society for surgery of the hand version of the quick disability of the arm, shoulder, and hand (QuickDASH-JSSH) questionnaire. J Orthop Sci 11:248-253

Johnson GW, Cadwallader K, Scheffel SB, Epperly TD (2007) Treatment of lateral epicondylitis. Am Fam Physician 76:843-848

Kraushaar B, Nirschl R (1999) Tendinosis of the elbow (tennis elbow). Clinical features and findings of histological, immunohistochemical, and electron microscopy studies. J Bone Joint Surg Am 81:259-278

Kurppa K, Viikari-Juntura E, Kuosma E, Huuskonen M, Kivi P (1991) Incidence of tenosynovitis or peritendinitis and epicondylitis in a meat-processing factory. Scand J Work Environ Health 17:32-37

Leclerc A, Landre MF, Chastang JF, Niedhammer I, Roquelaure Y, Study Group on Repetitive Work (2001) Upper-limb disorders in repetitive work. Scand J Work Environ Health 27:268-278

Ljung BO, Lieber RL, Fridén J (1999) Wrist extensor muscle pathology in lateral epicondylitis. J Hand Surg Br 24:177-183

March HC, Gilbert PD, Kain TM (1957) Hypercholesterolemic xanthoma of the tendon. AJR Am J Roentgenol 77:109

McCormack RR Jr, Inman RD, Wells A, Berntsen C, Imbus HR (1990) Prevalence of tendinitis and related disorders of the upper extremity in a manufacturing workforce. J Rheumatol 17:958-964
Nakamura K (2009) Locomotive syndrome: disability-free life expectancy and locomotive organ health in a "super-aged" society. J Orthop Sci 14:1-2. doi:10.1007/s00776-008-1302-y

Nirschl RP, Ashman ES (2004) Tennis elbow tendinosis (Epicondylitis). Instr Course Lect 53:587-598

Ogihara T, Kikuchi K, Matsuoka H, Fujita T, Higaki J, Horiuchi M et al (2009) The Japanese society of hypertension guidelines for the management of hypertension (JSH 2009). Hypertens Res 32:3-107

Ono Y, Nakamura R, Shimaoka M, Hiruta S, Hattori Y, Ichihara G et al (1998) Epicondylitis among cooks in nursery schools. Occup Environ Med 55:172-179

Otani K, Takegami M, Fukumori N, Sekiguchi M, Onishi Y, Yamazaki S et al (2012) Locomotor dysfunction and risk of cardiovascular disease, quality of life, and medical costs: design of the Locomotive Syndrome and Health Outcome in Aizu Cohort Study (LOHAS) and baseline characteristics of the study population. J Orthop Sci 17:261-271. doi:10.1007/ s00776-012-0200-5

Safran MR, Graham SM (2002) Distal biceps tendon ruptures: incidence, demographics, and the effect of smoking. Clin Orthop Relat Res 404:275-283

Sesto ME, Radwin RG, Block WF, Best TM (2006) Upper limb dynamic responses to impulsive forces for selected assembly workers. J Occup Environ Hyg 3:72-79

Shiri R, Viikari-Juntur E, Varonen H, Heliövaara M (2006) Prevalence and determinants of lateral and medial epicondylitis: a population study. Am J Epidemiol 164:1065-1074. doi:10.1093/aje/kwj325

Siddiqui MA, Koh J, Kua J, Cheung T, Chang P (2011) Functional outcome assessment after open tennis elbow release: what are the predictor parameters? Singapore Med J 52:73-76

Titchener AG, Fakis A, Tambe AA, Smith C, Hubbard RB, Clark DI (2013) Risk factors in lateral epicondylitis (tennis elbow): a case-control study. J Hand Surg Eur 38:159-164. doi:10.1177/1753193412442464

Verhaar JA (1994) Tennis elbow. Anatomical, epidemiological and therapeutic aspects. Int Orthop 18:263-267

Viikari-Juntura E, Kurppa K, Kuosma E, Huuskonen M, Kuorinka I, Ketola R et al (1991) Prevalence of epicondylitis and elbow pain in the meat-processing industry. Scand J Work Environ Health 17:38-45

Walker-Bone KE, Palmer KT, Reading I, Cooper C (2003a) Criteria for assessing pain and nonarticular soft-tissue rheumatic disorders of the neck and upper limb. Seminars Arthritis Rheum 33:168-184

Walker-Bone KE, Palmer KT, Reading I, Cooper C (2003b) Soft-tissue rheumatic disorders of the neck and upper limb: prevalence and risk factors. Seminars Arthritis Rheum 33:185-203

Walker-Bone K, Palmer KT, Reading I, Coggon D, Cooper C (2004) Prevalence and impact of musculoskeletal disorders of the upper limb in the general population. Arthritis Rheum 51:642-651

Walker-Bone K, Palmer KT, Reading I, Coggon D, Cooper C (2012) Occupation and epicondylitis: a population-based study. Rheumatology (Oxford) 51:305-310. doi:10.1093/rheumatology/ker228

Werner RA, Franzblau A, Gell N, Ulin SS, Armstrong TJ (2005) A longitudinal study of industrial and clerical workers: predictors of upper extremity tendonitis. J Occup Rehabil 15:37-46

\section{Submit your manuscript to a SpringerOpen ${ }^{\odot}$ journal and benefit from:}

- Convenient online submission

$\checkmark$ Rigorous peer review

- Immediate publication on acceptance

- Open access: articles freely available online

- High visibility within the field

- Retaining the copyright to your article

Submit your next manuscript at $>$ springeropen.com 